\title{
NOTIFICANDO O MEDO: CARTOGRAFIA E PERCEPÇÃO DA COVID-19 NA MALHA RODOVIÁRIA NA PORÇÃO NORTE DOS VALES DOS RIOS ARAGUAIA E TOCANTINS
}

\author{
NOTIFYING FEAR: CARTOGRAPHY AND PERCEPTION OF COVID-19 IN THE HIGHWAY \\ NETWORK IN THE NORTHERN PORTION OF THE ARAGUAIA AND TOCANTINS RIVER \\ VALLEYS
}

\author{
Vinicius Gomes de Aguiar \\ Doutor, Programa de Pós-graduação em Estudos de Cultura e Território \\ Universidade Federal do Tocantins- Araguaína \\ vinicius.aguiar@uft.edu.br \\ Dernival Venâncio Ramos Júnior \\ Doutor, Programa de Pós-graduação em Estudos de Cultura e Território \\ Universidade Federal do Tocantins- Araguaína \\ dernivaljunior@gmail.com \\ Kênia Gonçalves Costa \\ Doutora, Programa de Pós-graduação em Estudos de Cultura e Território \\ Universidade Federal do Tocantins- Araguaína \\ keniacost@uft.edu.br \\ Reges Sodré da Luz Silva Dias \\ Doutorando, Programa de Pós-Graduação em Geografia \\ Universidade Federal de Goiás \\ regessodre@gmail.com
}

\begin{abstract}
RESUMO
Este trabalho espacializa a evolução das notificações dos casos de COVID-19 em Araguaína. Também descreve a percepção sobre a pandemia a partir do contexto das relações com as cidades e a malha rodoviária existente na porção norte dos vales dos rios Araguaia e Tocantins, que compreende o norte do estado do Tocantins, o sudeste do estado do Pará e sul do Maranhão. Os dados utilizados para entender a evolução das notificações de COVID19 foram disponibilizados pelas Secretarias Estaduais de Saúde do Tocantins e Maranhão, assim como pelas prefeituras municipais paraenses devido a incompatibilidade com os números apresentados pelo estado do Pará. Esses dados foram organizados cartograficamente para auxiliar no entendimento de como o contexto espacial dos casos de COVID-19 de Araguaína podem estar conectados com comportamento regional na proliferação do vírus, bem como sua incidência por 100 mil habitantes, apontando que a conexão por meio da malha rodoviária regional e o fluxo social desse território induzem no aumento contínuo dos casos de COVID-19. Outro procedimento que auxiliou na compreensão da relação de Araguaína com este espaço foi a aplicação de questionários relacionado à percepção das pessoas dessas cidades em relação ao COVID-19, onde foi destacado que na porção norte dos vales, o medo é a imagem mental preponderante sobre a pandemia. Esses dois conjuntos de dados ajudam a conhecer as duas dimensões significativa da Pandemia no interior do país.
\end{abstract}

Palavras-chave: COVID-19. Vales dos rios Araguaia e Tocantins. Cartografia. Percepção.

\begin{abstract}
This work spacializes the evolution of COVID-19 notification and describes the perception of the pandemic in Araguaína. This city has relations with the cities and the road network of the north of Vales dos rios Araguaia e Tocantins region that comprises the north of the state of Tocantins, the southeast of the state of Pará and the south of Maranhão. The data used to understand the evolution of COVID-19 notifications were made available by the Health's
\end{abstract}

Recebido em: 02/05/2020

Aceito para publicação em: 21/05/2020. 
Secretaries of states of Tocantins and Maranhão, and by some city halls of Pará because of the incompatibility with the numbers presented by the state. These data were organized cartographically to help understand the relation between the spatial context of COVID-19 cases in Araguaína and the regional behavior with the virus proliferation as well as its incidence per 100 thousand inhabitants. In other words, the cities connection by road network and social flow help to increase COVID-19 cases. Another procedure that helped this work was the application of questionnaires related to the people's perception of COVID-19 in this region. As a result, the fear as the preponderant mental image about the pandemic. These data help us to understand the significant dimensions of the pandemic in the north of Vales dos rios Araguaia e Tocantins region.

Keywords: COVID-19, Vales dos rios Araguaia e Tocantins. Cartography. Perception.

\section{INTRODUÇÃO}

Propomo-nos neste trabalho descrever as notificações dos casos de COVID-19 e a percepção sobre a pandemia em Araguaína considerando o contexto da porção norte dos vales dos rios Araguaia e Tocantins. Segundo historiadores (CORMINEIRO, 2015; GUILHERME VELHO, 2013), esses rios constituíram-se em locais de aglutinação e de fluxos populacionais diversos, inclusive indígenas, quilombolas e outras comunidades tradicionais. A região compreende uma porção norte do Tocantins, Sul do Maranhão e Sudeste do Pará.

A pesquisa usa de dois procedimentos: o primeiro foi o cartográfico. Foram representados fenômenos qualitativa e quantitativa (método das figuras geométricas proporcionais, com manifestação em ponto) de forma temporal (entre os dias cinco de abril e primeiro de maio de dois mil e vinte) (MARTINELLI, 2009). O cruzamento desses dois métodos possibilitou estabelecer correlação entre casos notificados e a malha viária que sustentam as conexões urbanas. O segundo procedimento, consistiu na aplicação de formulário (entre os dias vinte e um e vinte e três de abril de dois mil e vinte) através de meio digital para viabilizar o acesso a uma mostra mais qualificada, produzimos os dados considerados a seguir.

O texto está dividido em três partes. Em primeiro lugar, fazemos uma caracterização da porção norte dos Vales para em seguida, descrever os dados cartográficos de notificações da COVID-19, bem como sua incidência por 100 mil habitantes, e, por fim, descrevemos e tecemos considerações sobre os dados resultantes do formulário, o qual foi aplicado em dezenove municípios da região, em meio digital que dizem respeito à percepção da pandemia.

\section{CARACTERIZAÇÃO DA PORÇÃO NORTE DOS VALES DOS RIOS ARAGUAIA E TOCANTINS}

A partir do século XIX e, de modo especial, na segunda metade do século XX, migrações e ações do Estado Nacional acabaram por constituir a porção norte dos Vales em um dos entroncamentos mais importantes do centro norte do país. No espaço de encontro entre os rios, também entre os estados do Pará, Maranhão e Tocantins, a partir de 1960, constituiu-se importante malha rodoviária e urbana, com o deslocamento dos polos econômicos das cidades ribeirinhas (AQUINO, 2004) como Tocantinópolis (TO), Carolina (MA), Araguatins (TO) e São João do Araguaia (PA) para cidades como Araguaína (TO), Marabá (PA), Imperatriz (MA), Açailândia (MA), Parauapebas (PA) e Balsas (MA) situadas às margens das rodovias, como as BRs 153, 226, 010 e 230.

Esse entroncamento urbano e rodoviária possui uma importante integração interna, com interações de centros locais e sub-regionais entre eles e em direção às cidades regionais, Araguaína, Marabá e Imperatriz. Os fluxos em busca de bens e serviços não respeitam as fronteiras estaduais, o que no caso da regionalização dos serviços de saúde implica frequentemente em conflitos de jurisdição. Além disso, são fluxos que percorrem frequentemente grandes distâncias, em virtude do tamanho das áreas municipais e da própria região.

As cidades regionais referidas atuam entre si ora em relação de complementariedade, ora de competição. Por exemplo, se Araguaína é um polo de saúde, Imperatriz e Marabá prestam serviços aeroportuários para a região. Do mesmo modo, cidades como Araguaína, Imperatriz e Marabá são núcleos agropecuários e emergem importantes centros-sub regionais, como Balsas que se destaca pela produção de grãos e Parauapebas e Açailândia que são centros de atração de mão de obra regional pelos empreendimentos relacionados ao polo mineral de Carajás. 
Mas, essas cidades também disputam o mercado consumidor regional, seja ele varejista ou atacadista. Isso pode ser ilustrado quando se observa cidades como São Geraldo do Araguaia, cujas demandas se direciona a Marabá e Araguaína; bem como Tocantinópolis, que procura Imperatriz e Araguaína, simultaneamente. Também, os gestores dessas cidades elaboram representações que visam atrair consumidores, como o marketing "Araguaína, a capital econômica do Tocantins".

$\mathrm{Na}$ base da rede de cidades dessa região encontra-se uma diversidade de centros cuja atividades atendem apenas a população do próprio município ou daqueles vizinhos. Boa parte desses municípios ainda têm maioria da população residindo no espaço rural, com estradas vicinais em péssimas condições e distâncias a serem percorridas até a sede municipal, especialmente no Pará, que podem chegar a $100 \mathrm{~km}$. Nesses municípios predominam atividades agropecuárias, sendo que o funcionalismo público representa parte significativa das ocupações no espaço urbano.

Em combinação, as cidades da região, localizadas em um raio de 300 quilômetros de Araguaína, possuem mais de um milhão e oitocentos mil (1,8 milhões) habitantes, segundo do censo do IBGE (2010) e o PIB per capita de R $\$ 28.631,99$ (IBGE, 2017).

\section{A CARTOGRAFIA DAS NOTIFICAÇÕES}

Nesta seção, descreveremos a espacialização das notificações de casos de COVID-19 de cinco de abril a primeiro de março de 2020.

De acordo com a OMS - Organização Mundial de Saúde, o principal elemento do protocolo de combate a pandemia é o distanciamento social. Esforço prévio (BRITO e SODRÉ, 2020; VITAL, 2020) de sistematização indicam, por um lado, os desafios à manutenção do distanciamento social em cidades como Araguaína, o que pode ser estendido para os outros centros regionais, Marabá e Imperatriz.

Desde o surgimento dos primeiros casos de COVID-19 no Tocantins, temos realizado a coleta de dados nas secretarias de saúde e produzidos representações cartográficas diárias de distribuição quantitativa na porção norte dos Vales. Utilizou-se a representação cartográfica como forma de apresentação dos números dos casos de COVID-19, assim como a representação proporcional de casos para cada 100 mil habitantes por município, mesmo em municípios de população inferior a esse quantitativo, pois apesar do mapa ser uma representação incompleta do terreno (JOLY, 1990), ou seja, uma simplificação da realidade, o mapa permite atuar nas comunicações científicas de análise espaço-temporal, por meio da seleção de informações e dos princípios metodológicos da semiologia gráfica.

A organização dos dados numéricos dos casos de COVID-19 ocorridos nos municípios inseridos na porção norte dos Vales foram buscados nos números apresentados pelas Secretarias Estaduais de Saúde do Tocantins e do Maranhão. Nos dados do Pará, a secretaria estadual apresentou diferenças significativas dos dados disponibilizados pelos municípios, logo, definimos que neste estado os dados seriam coletados nas plataformas de comunicação das prefeituras municipais.

Inicialmente esses mapas, produzidos diariamente, foram usados em material de divulgação e alerta quanto à necessidade de prevenção ${ }^{2}$ (NEUZA/UFT, 2020; UFT, 2020). Ao observar os dados representados espacialmente, começamos a levantar questões quanto às diferenças de notificações entre os diversos núcleos regionais como Araguaína e Imperatriz, que registraram crescimento no número de casos superior a dezoito e oitenta e duas vezes, respectivamente, ao considerar os números entre os dias cinco de abril a primeiro de maio de 2020.

A organização diária dos dados se iniciou no dia cinco de abril, momento em que Palmas registrava doze casos e Araguaína quatro, apresentando-se como os maiores números de casos na área observada, sendo que Marabá, Parauapebas e Imperatriz apresentavam dois casos (Figura 1). Até esse momento, conforme os boletins epidemiológicos, o processo de contágio estava ligado aos casos importados, isto é, de pessoas com histórico de viagens e aqueles com os quais tiveram contato.

Nove dias depois (14/4), momento em que o presidente da república intensifica o embate contra o Ministério da Saúde devido ao desentendimento sobre as regras de distanciamento social relacionado ao combate da proliferação da COVID-19, Araguaína decide por permitir o funcionamento de restaurantes e academias, mas com restrições, pois possuía apenas seis casos. Palmas aumenta para dezessete, Marabá mantém-se em dois, enquanto Parauapebas/PA e Imperatriz/MA, respectivamente,

2 Informações disponibilizadas em redes sociais com intuito de uma divulgação mais horizontal. Ver: https://www.instagram.com/neuza_comunidades/?igshid=n4togi8gd4gr; https://www.facebook.com/NEUZAUFT/ DOl:http://dx.doi.org/10.14393/Hygeia0054395 Hygeia Edição Especial: Covid-19, Jun./2020 p.153 - 163, pág.155 
alcançam doze (seis vezes maior que no dia cinco) e quatorze (sete vezes maior que no dia cinco). Neste mesmo dia a cidade de Tocantinópolis, que faz divisa com o estado do Maranhão, registra o primeiro caso.

Após a organização desses números na forma de mapas, tornou-se perceptível que o distanciamento social estava desautorizado pelo chefe do executivo federal. Nos dias seguintes, observando a proliferação de caso, percebemos que através da malha viária da porção norte dos Vales, a COVID-19 estava se alastrando por todo este território (Figura 1).

Nas cidades núcleos haviam sido identificados os primeiros casos, mas com o passar dos dias, as cidades situadas entre esses núcleos, quase sempre pequenas, passaram a registrar os primeiros casos, como em Nova Ipixuna (PA), São João do Araguaia (PA) e Sítio Novo do Tocantins (TO). Realidade que apontam o deslocamento social por meio das rodovias como fator potencializador da proliferação da COVID-19 nas cidades observadas, confirmando o que afirmam Brito e Sodré (2020). As pequenas cidades dependem dos serviços ofertados nos núcleos regionais de modo que esse fato pode agir como elemento de difusão do vírus.

Já no dia vinte e um de abril, Parauapebas notificou trinta e oito caso e Imperatriz, quarenta e sete. Os casos notificados mais que triplicaram, ultrapassando a capital do Tocantins, então com 25 casos notificados. Neste dia Marabá dobrou (de dois foi para quatro casos) a quantidade registrada da semana anterior, enquanto Araguaína se mantém com seis casos. Nessas primeiras cidades, a transmissão comunitária já estava estabelecida.

Figura 1 - Espacialização dos casos de COVID-19, no dia cinco de abril de da porção norte dos vales dos rios Araguaia e Tocantins.

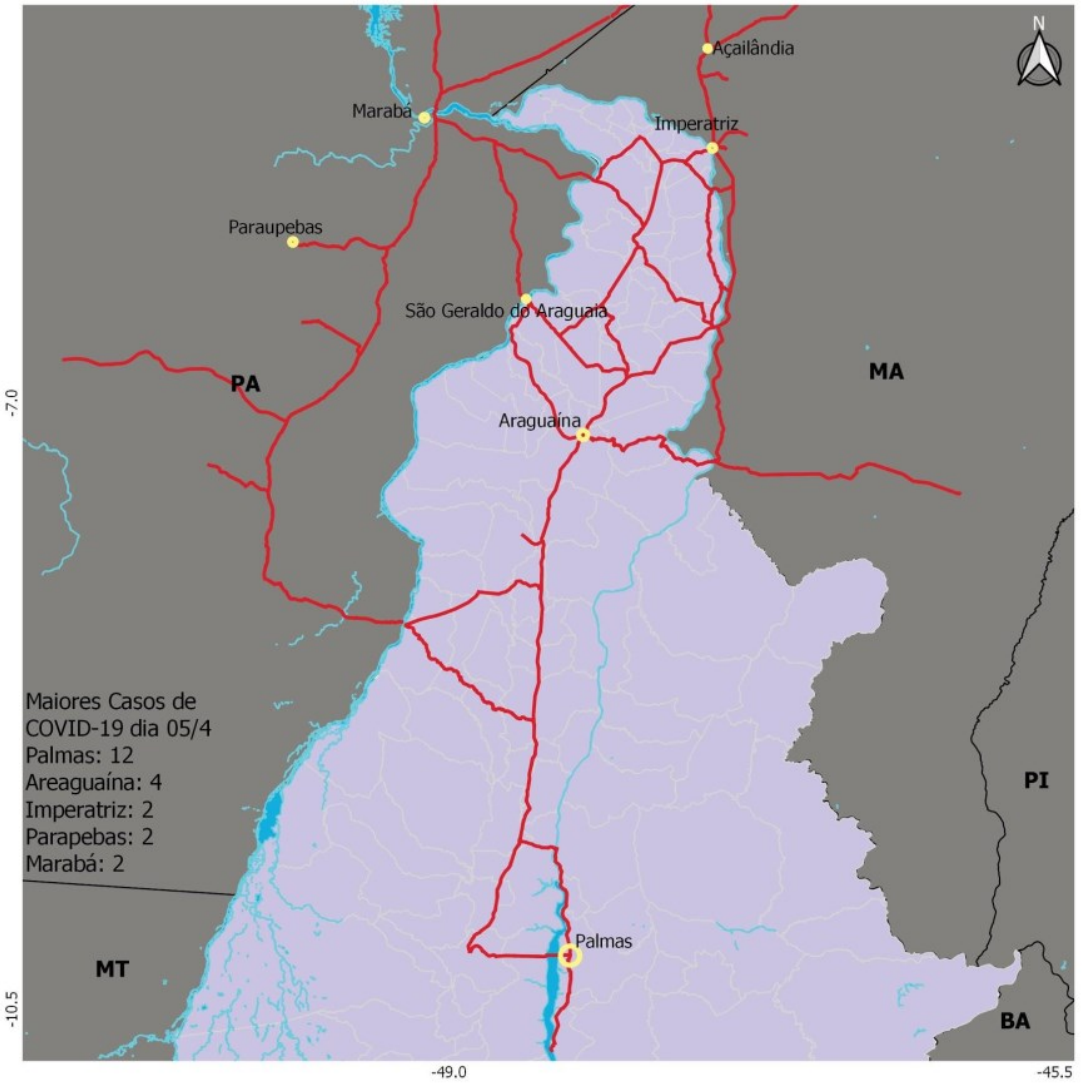

\section{Casos de COVID-19 Nas Cidades do Norte dos Vales dos Rios Araguaia e Tocantins - 05/04/2020}

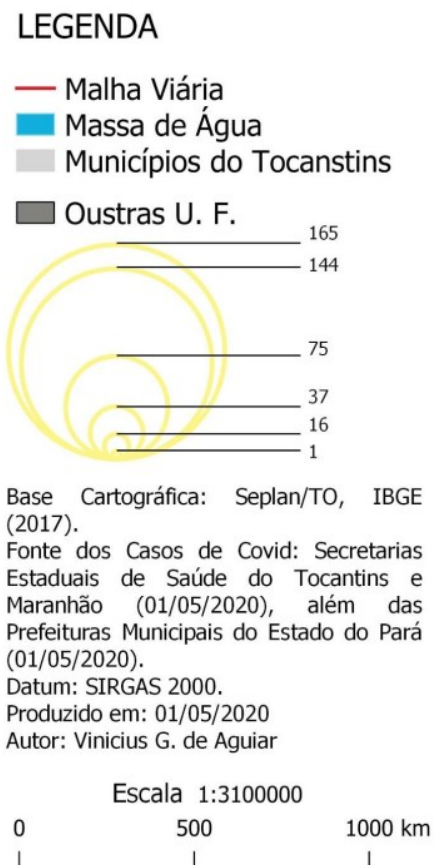

Fonte dos dados relacionado aos casos notificados de COIVID-19: Secretaria Estadual de Saúde do Tocantins, Secretaria Estadual de Saúde do Maranhão e Prefeituras Municipais de Parauapebas, São Geraldo do Araguaia e Marabá. Elaboração: Autores, 2020. 
Como os números de casos da semana do dia vinte e um eram considerados baixos, no dia vinte e oito, a cidade de Araguaína mudou de posição. Quatorze dias após abertura intensa das atividades comerciais (incluindo restaurantes e academias), foram registrados quarenta e seis casos. Um crescimento de mais de sete vezes no número da semana anterior (Figura 2), praticamente igualando o número de casos de Palmas (TO).

Com essa realidade, no dia seguinte (vinte e nove) a prefeitura decidiu por fechar novamente as atividades comerciais. Em primeiro de maio Araguaína registrou mais de sessenta por cento de aumento de casos, em relação ao dia vinte e oito, alcançando setenta e cinco casos, nove a mais que a capital (Palmas).

Essas observações nos permitem identificar alguns padrões de difusão regional do vírus até o momento: ele tem se concentrado nos centros regionais, Palmas, Araguaína, Imperatriz e Marabá. A partir deles, há uma concentração de casos em centros sub-regionais, como Redenção, Balsas, Conceição do Araguaia e Açailândia. Parauapebas, embora tenha uma região de centralidade pequena, foge a essa regra em virtude, ao que parece, do tamanho populacional, das interações espaciais de longo alcance que estabelece, devido às atividades corporativas presentes em seu território e do intenso fluxo de mão de obra, além de falhas nas medidas de isolamento.

Um terceiro nível de materialização do vírus são as cidades pequenas, que de forma geral, ainda apresentam pouquíssimos casos. Mas, essas cidades estão até o momento, situadas ou as margens de importantes rodovias regionais ou em suas proximidades. Há um eixo principal que vai de Araguaína a Açailândia, incluindo desde Wanderlândia, Estreito e Governador Edison Lobão. A nordeste de Marabá, inicia-se também a proliferação do vírus, em direção a Dom Eliseu. Outro arco começa a se formar ao sul de Parauapebas, que vai até as proximidades de Conceição do Araguaia.

Figura 2 - Espacialização dos casos de COVID-19, no dia vinte de abril de 2020, da porção norte dos vales dos rios Araguaia e Tocantins.

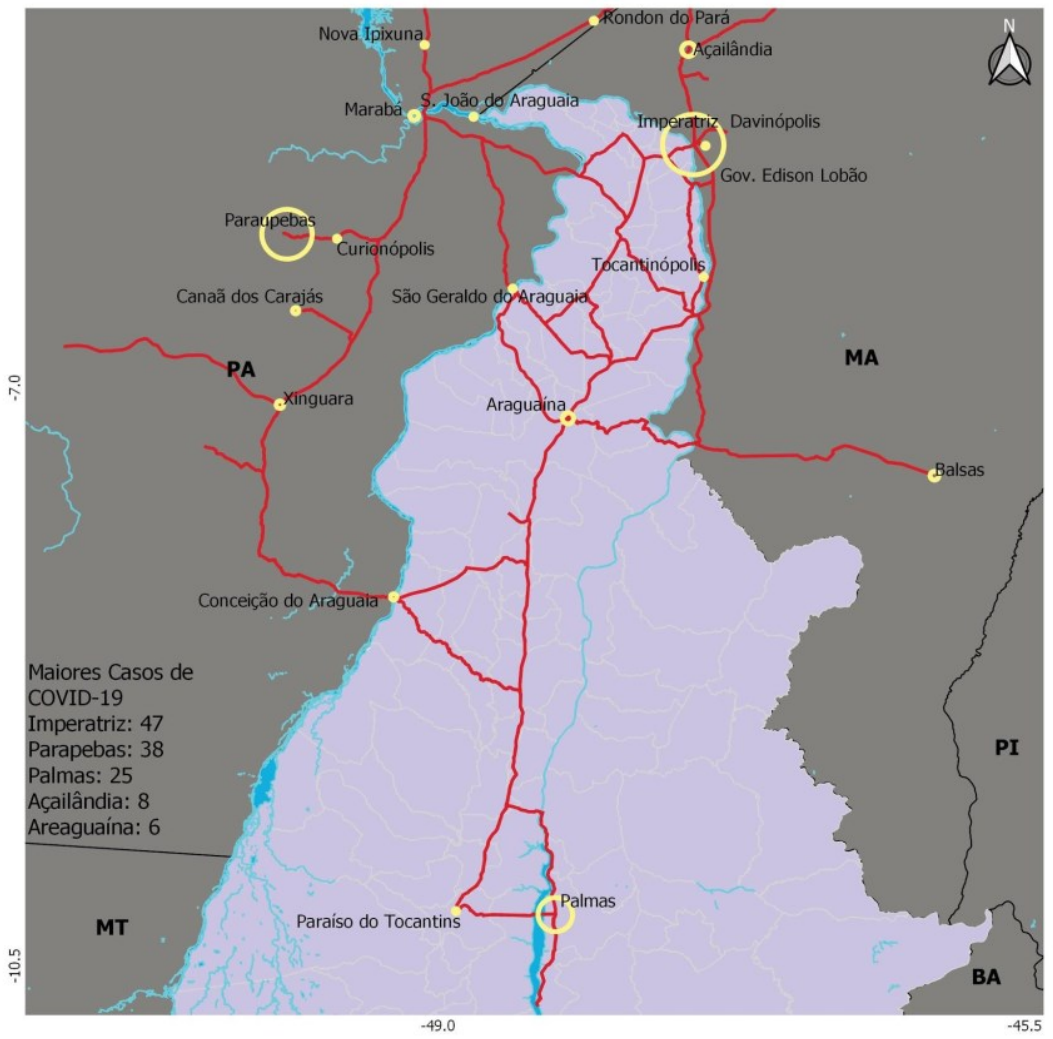

\section{Casos de COVID-19 Nas Cidades do Norte dos Vales dos Rios Araguaia e Tocantins - 21/04/2020}

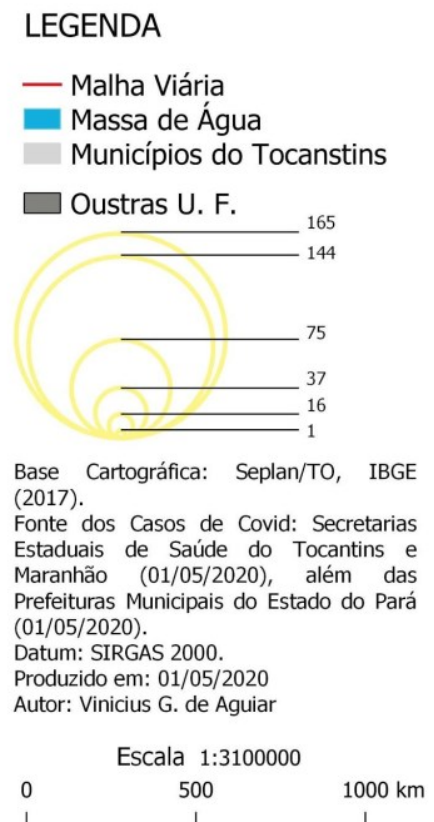

Fonte dos dados relacionado aos casos notificados de COIVID-19: Secretaria Estadual de Saúde do Tocantins, Secretaria Estadual de Saúde do Maranhão e Prefeituras Municipais de Parauapebas, São Geraldo do Araguaia, Marabá, Xinguara, Canaã dos Carajás, Curionópolis, São João do Araguaia, Conceição do Araguaia, Nova Ipixuna e Rondon do Pará. Elaboração: Autores, 2020.

Hygeia Edição Especial: Covid-19, Jun./2020 p.153 - 163, pág.157 
Além das facilidades de fluidez dessas pequenas cidades, elas são ponto de paragem para caminhoneiros, transporte interestadual de passageiros e de abastecimento de veículos particulares, o que facilita a proliferação do vírus. Há, igualmente, o início da concentração de casos no entorno de Imperatriz e, um pouco menos de Marabá, é sugestivo de interações intensas entre a cidade regional e a local, com fluxo diário de trabalhadores e de procura por consumo de primeira necessidade (Figura 3).

Ao observados os dados a partir da incidência por cem mil habitantes - na região poucas cidades possuem população desse tamanho - conforme tratado em dados disponibilizados pelo Ministério da Saúde, até o dia primeiro de maio a cidade de Parauapebas apresenta maior incidência de casos por cem mil habitantes $(69,1)$, seguida por Imperatriz $(63,8)$ e Araguaína $(41,5)$.

Porém se aplicarmos a mesma proporção a todos municípios da região analisada, ou seja, se estimarmos a proporção de incidência de COVID-19 a locais de população baixa caso o município possuísse cem mil habitantes, entre as dez cidades com maior incidência na região (superior a quarenta casos para cada cem mil habitantes), sete estão com menos de quarenta mil habitantes de acordo com estimativa populacional do IBGE (2019).

Assim Tabocão-TO, localizada às margens da rodovia Belém-Brasília (BR-153), com um pouco mais que dois mil e quinhentos habitantes e que possui um posto de combustível muito utilizado como parada para alimentação, dormitório e abastecimento de pessoas em caminhões, ônibus e vans que cruzam o norte do Tocantins, não poucas vezes vindas dos estados do Pará e Maranhão, lidera o ranking geral de incidência na região $(154,5)$ caso possuísse cem mil habitantes, estando acima da média nacional (103) e da estadual (75).

Figura 3 - Espacialização dos casos de COVID-19, no dia primeiro de maio de 2020, da porção norte dos vales dos rios Araguaia e Tocantins.

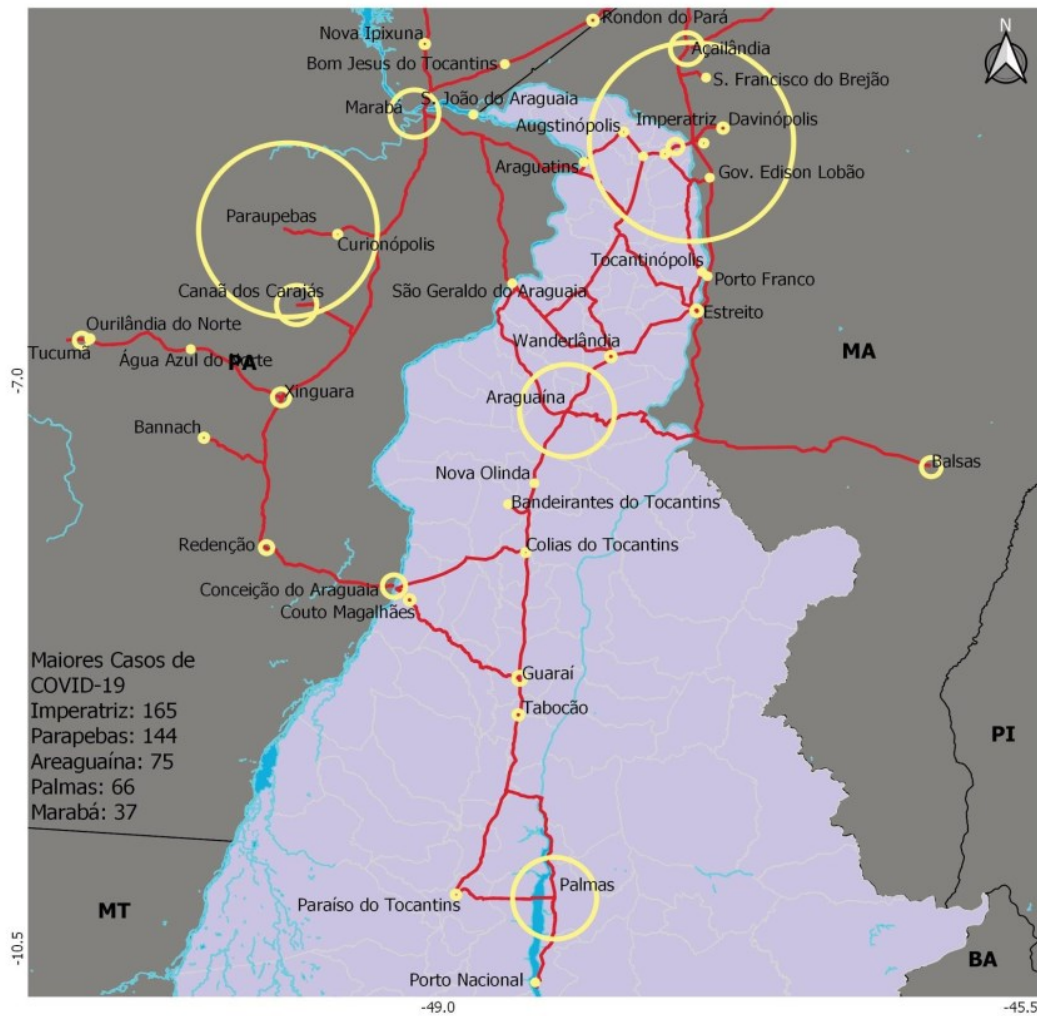

\section{Casos de COVID-19 Nas Cidades do Norte dos Vales dos Rios Araguaia e Tocantins - 01/05/2020}

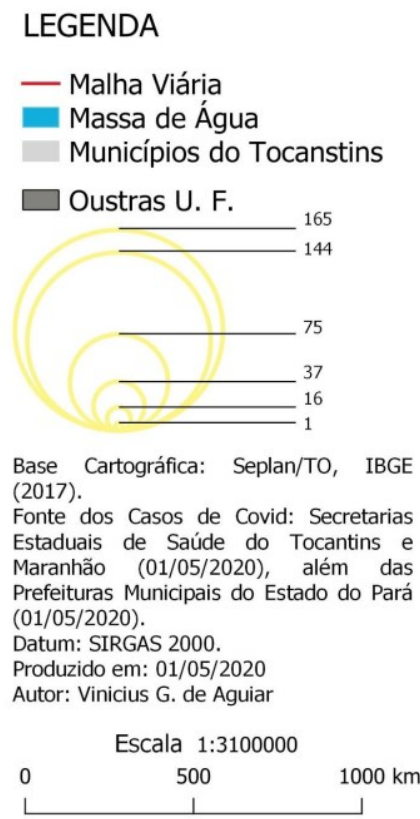

Fonte dos dados relacionado aos casos notificados de COIVID-19: Secretaria Estadual de Saúde do Tocantins, Secretaria Estadual de Saúde do Maranhão e Prefeituras Municipais de Parauapebas, Tucumã, Água Azul do Norte, Bannach, Redenção, Bom Jesus do Tocantins, Ourilândia do Norte, São Geraldo do Araguaia, Marabá, Xinguara, Canaã dos Carajás, Curionópolis, São João do Araguaia, Conceição do Araguaia, Nova Ipixuna e Rondon do Pará. Elaboração: Autores, 2020. 
Das dez primeiras cidades mais atingidas proporcionalmente pelo COVID-19 (incluindo cidades que não possuem cem mil habitantes, mas que tiveram um cálculo proporcional realizado), apenas Bannach-PA, na segunda posição $(121,7)$, está situada fora dos principais eixos de contaminação do vírus e do entorno de cidades regionais ou sub-regionais que são focos de contaminação. Embora minoritário, esse caso nos chama a atenção para a proliferação do vírus em algumas localidades com difícil acesso a serviços de saúde e forte "solidariedade orgânica" (SANTOS, 1996, p. 231).

Canaã do Carajás-PA, situada no entorno de Parauapebas e com intensas interações com esta cidade, sobretudo pela atuação da Vale ${ }^{3}$ nos dois municípios, é a terceira cidade com maior incidência $(80,9)$. Em quarto lugar aparece São Miguel do Tocantins-TO $(74,1)$, localizada no entorno de Imperatriz. Completam esse ranking das 10 mais atingidas Couto Magalhães-TO $(71,6)$, estabelecida no eixo que liga o estado do Tocantins a Redenção-PA e Parauapebas-PA; Cariri do Tocantins-TO $(45,6)$ e Wanderlândia-TO $(34,2)$, ambas situadas ao longo da Belém-Brasília, a primeira é conhecida pela elevada produção de grãos no Tocantins e está no entorno de Gurupi-TO, em sua porção meridional, enquanto a última, nas proximidades de Araguaína, em sua borda setentrional (Figura 4 e Quadro 1).

Figura 4 - Espacialização da proporção dos casos de COVID-19 para cada 100 mil habitantes nas cidades do Norte do Tocantins, no dia primeiro de maio de 2020, da porção norte dos vales dos rios Araguaia e Tocantins.

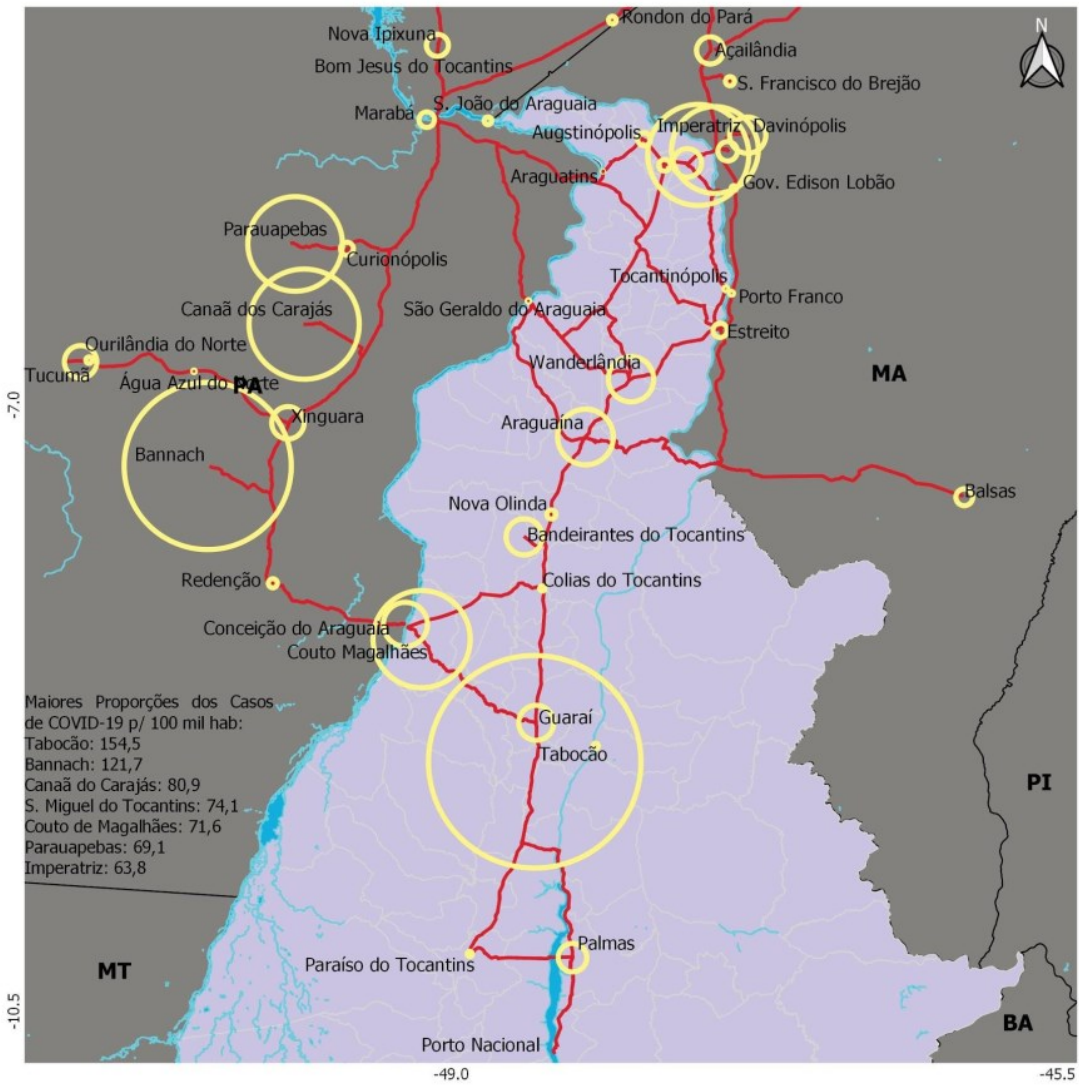

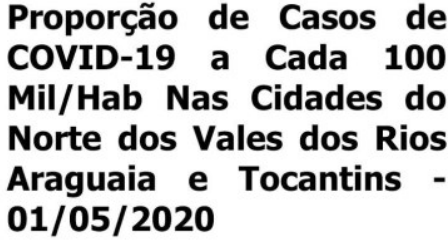

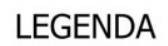

- Malha Viária

Massa de Água

Municípios do Tocanstins

Oustras U. F.
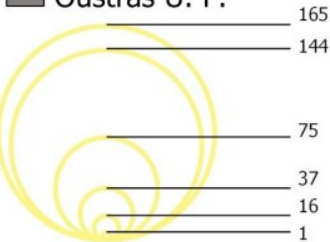

Base Cartográfica: Seplan/TO, IBGE (2017).

Fonte dos Casos de Covid: Secretarias Estaduais de Saúde do Tocantins e Maranhão (01/05/2020), além das Prefeituras Municipais do Estado do Pará (01/05/2020).

Datum: SIRGAS 2000.

Produzido em: 17/05/2020

Autor: Vinicius G. de Aguiar

$\begin{array}{lcc} & \text { Escala } 1: 3100000 \\ 0 & 500 & 1000 \mathrm{~km}\end{array}$

Fonte dos dados relacionado aos casos notificados de COIVID-19: Secretaria Estadual de Saúde do Tocantins, Secretaria Estadual de Saúde do Maranhão e Prefeituras Municipais de Parauapebas, Tucumã, Água Azul do Norte, Bannach, Redenção, Bom Jesus do Tocantins, Ourilândia do Norte, São Geraldo do Araguaia, Marabá, Xinguara, Canaã dos Carajás, Curionópolis, São João do Araguaia, Conceição do Araguaia, Nova Ipixuna e Rondon do Pará. Elaboração: Autores, 2020.

\footnotetext{
${ }^{3}$ A Vale é uma empresa privada que atua na mineração, logística (ferrovias, portos, terminais e infraestrutura), energia e em siderurgia (http://www.vale.com/brasil/PT/aboutvale/Paginas/default.aspx).
} 
Quadro 1 - Dez maiores proporções de casos de COVID-19 para cada cem mil habitantes no dia primeiro de maio, estimativa populacional em julho de dois mil e dezenove e número de casos por município dos vales dos rios Araguaia e Tocantins em primeiro de maio.

\begin{tabular}{|l|c|c|c|}
\hline Municípios & $\begin{array}{c}\text { Estimativa } \\
\text { Populacional (2019) }\end{array}$ & $\begin{array}{c}\mathbf{N}^{\circ} \text { de casos } \\
\text { em 01/05 }\end{array}$ & $\begin{array}{c}\text { Casos de COVID-19 para } \\
\text { cada cem mil habitantes }\end{array}$ \\
\hline Tabocão-TO & 2589 & 4 & 154,4998 \\
\hline Bannach-PA & 3286 & 4 & 121,7285 \\
\hline Canaã do Carajás-PA & 37085 & 30 & 80,89524 \\
\hline São Miguel do Tocantins-TO & 12139 & 9 & 74,1412 \\
\hline Couto de Magalhães-TO & 5588 & 4 & 71,58196 \\
\hline Parauapebas-PA & 208273 & 144 & 69,14002 \\
\hline Imperatriz-MA & 258682 & 165 & 63,78488 \\
\hline Cariri do Tocantins-TO & 4382 & 2 & 45,64126 \\
\hline Araguaína-TO & 180470 & 75 & 41,55815 \\
\hline Wanderlândia-TO & 11683 & 4 & 34,23778 \\
\hline
\end{tabular}

Fonte dos dados relacionado aos casos notificados de COIVID-19: Secretaria Estadual de Saúde do Tocantins, Secretaria Estadual de Saúde do Maranhão e Prefeituras Municipais de Parauapebas, Bannach e Canaã dos Carajás. Elaboração: Autores, 2020.

\section{A PERCEPÇÃO DA PANDEMIA}

A disputa política sobre o distanciamento social pode ser percebida como uma guerra de representações (CHARTIER, 1998). Para conhecer a percepção sobre a pandemia neste contexto, lançamos mão de formulário com vinte e uma (21) questões. Foi usado o instrumento formulário do google, que foi enviado pelas redes sociais para pessoas das diversas cidades da porção norte dos Vales, região no qual organizamos a cartografia.

Foram preenchidos cento e cinquenta e cinco (155) formulários em dezenove (19) municípios diferentes. Em Araguaína foram preenchidos noventa e nove (99) formulários, onze (11) em Redenção, nove (9) em Palmas, nove (9) em Imperatriz, dois (2) em Porto Nacional e dois (2) em Tocantinópolis. Os demais municípios registraram apenas um formulário preenchido.

Mais de oitenta por cento $(80 \%)$ das pessoas que responderam o formulário informaram possuir entre dezoito e cinquenta anos de idade, reflexo da juventude da população regional (IBGE, 2010). Contudo, é importante dizer que as perguntas que pretendiam conhecer quais as imagens mentais que as pessoas estão mobilizando em relação à pandemia, está conectada (RAMOS JÚNIOR, 2013) ao imaginário social e não à faixa etária.

Nos gráficos um e dois (1 e 2), podemos ver as imagens mentais que foram mobilizadas. Como esta pergunta era de múltipla escolha, às pessoas responderam em um formulário várias palavras nessa pergunta. Sendo assim, selecionamos as palavras que mais se repetiram entre as respostas. Consideramos estas palavras imagens mentais, houve um grupo de três imagens mentais que preponderam: morte, medo, isolamento. Isso se repetiu em todas as cidades. Quanto os afetos tematizados, o medo (com trinta e sete por cento - $37 \%$ ), foi o único afeto capaz de mobilizar mais que dez por cento (com dez por cento - 10\%) dos que responderam o formulário.

\footnotetext{
${ }^{4}$ Estimativa de 2019 publicada pelo IBGE. Disponível em:

https://www.ibge.gov.br/estatisticas/sociais/populacao/9103-estimativas-de-populacao.html?=\&t=o-que-e.
} 
Gráfico 1 - 10 palavras que vem à cabeça quando você pensa na Pandemia/Coronavírus/COVID-19? Em Araguaína-TO.

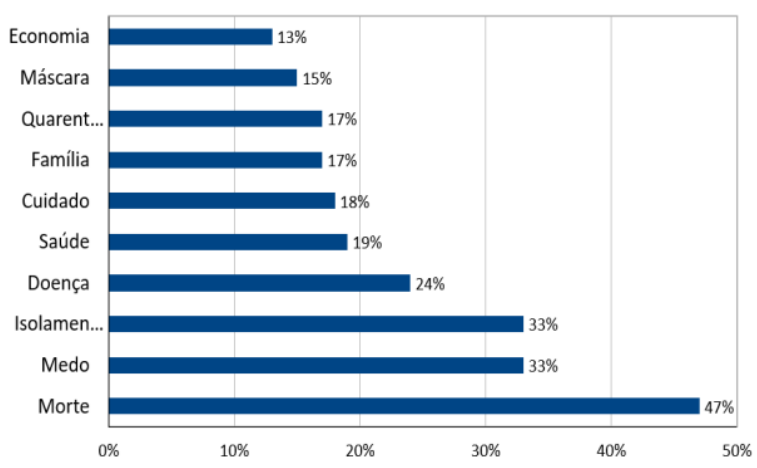

Gráfico 2 - 10 palavras que vem à cabeça quando você pensa na Pandemia/Coronavírus/ COVID-19? No entorno de Araguaína-TO.

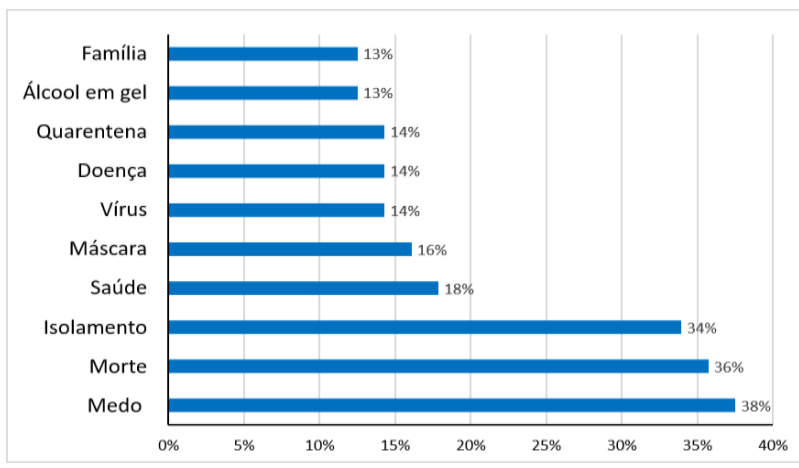

Fonte: Autores, 2020.

Os meios pelos quais esses sujeitos estão buscando informação sobre a pandemia no Brasil e na região foram respondidos em uma pergunta de múltiplas escolhas. Para buscar informações sobre Brasil, no caso dos residentes em Araguaína, utilizaram majoritariamente a televisão (com trinta e oito por cento $-38 \%$ ), os jornais on line (com trinta e três por cento - 33\%) e as redes sociais (com vinte e sete por cento - 27\%). Para os outros municípios saber sobre a COVID-19 no Brasil são utilizados primordialmente as redes sociais (com quarenta por cento - 40,91\%), a televisão (com trinta e quatro por cento $-34 \%$ ) e os jornais on line (com vinte e cinco por cento - $25 \%$ ).

No que diz respeito às notícias sobre a COVID-19 na própria região, no caso de Araguaína, usa-se na maioria dos casos as redes sociais (com trinta e sete por cento $37 \%$ ), a televisão (com trinta e quatro por cento $-34,74 \%$ ) e jornais on line (com vinte e sete por cento - $27 \%$ ), enquanto que as cidades do entorno buscam essas informações mantendo preferências com mais destaque para as redes sociais (com quarenta e sete por cento - $47 \%$ ), em seguida televisão (com vinte e sete por cento $27 \%$ ) e jornais on line (com vinte e cinco por cento - 25\%). Apesar da importância da televisão, as redes sociais e os jornais on line têm o maior protagonismo como espaços em que se busca informações.

A maioria (noventa e dois por cento - 92\%) apoia o distanciamento social e acredita que a ciência tem alto papel no combate à pandemia (noventa e dois por cento - 92\%). A religião, por outro lado, tem papel de baixa (trinta e dois por cento - 32\%) ou média (trinta e nove por cento - 39\%) importância no combate a COVID-19. Mesmo a amostra apontando certa tendência à laicidade (SILVA, 2019), se a percebermos como a negação do papel da religião e a crença na ciência, é possível que a guerra de representação entre sujeitos investidos de autoridade social como o chefe do executivo federal, as mídias e a ciência potencialize a desorientação social. Também é importante destacar o ostensivo noticiamento do crescimento de casos de forma exponencial no Brasil, Itália, Espanha e Estados Unidos pelos meios de comunicação como a televisão e redes sociais.

$\mathrm{Na}$ região, essa guerra de representação esteve materializada nas conflitantes orientações quanto ao distanciamento social: o fechamento, a reabertura do comércio e novamente fechamento do comércio em cidades como Marabá, Araguaína e Redenção (PA). Essa oscilação compromete uma política de contenção do vírus, pois os momentos de abertura podem ensejar fluxos de contaminação que posteriormente serão mais difíceis de serem controlados e podem custar centenas de vidas.

A crise política instalada entre o presidente e o ex-ministro da saúde, é materializada na região pela demora na instalação de hospitais de campanha (como em Araguaína na qual não foi instalados ainda), em Marabá em que o hospital havia sido instalado em quatorze de abril e Imperatriz em que o foi aberto em vinte e quatro de abril. Esses elementos podem estar conectados à sensação de insegurança e à desorientação e, por conseguinte, a instalação do medo e, conectado a ele, morte e isolamento. 
Contudo, o medo das epidemias é, historicamente, um dos maiores medos humanos como mostra Jean Delumeau (2009). Ele caracteriza o medo das epidemias como um dos medos mais arraigados no imaginário social. Na tipologia dos medos que o autor faz, o medo das epidemias é do tipo coletivo, é o medo de todos (DELUMEAU, 2009). Daí a maioria das pessoas que preencheram o formulário destaca o medo, porque correlacionam com outras imagens mentais como: doença, isolamento, solidão, vírus e colapso.

A esperança, contudo, deslocada da religião, centra-se na ciência. A única que tem alto protagonismo tanto na solução dos problemas quanto no encaminhamento do que fazer agora - o distanciamento social.

\section{CONSIDERAÇÕES FINAIS}

Este texto descreve e contextualiza as notificações dos casos de COVID-19 e a percepção sobre a pandemia na porção dos vales dos rios Araguaia e Tocantins. Os dados foram produzidos a partir de procedimentos metodológicos relacionados à cartografia e a aplicação de formulário através de meio digital para viabilizar o acesso a uma amostra mais qualificada.

Os dados apontam a malha rodoviária e o fluxo social desse território como conectados à expansão da COVID-19 na porção norte dos Vales dos Rios Araguaia e Tocantins, fronteira entre os estados do Pará, Maranhão e Tocantins. Percebe-se que o vírus segue uma difusão dos centros regionais para os sub-regionais e destes para as pequenas cidades, ao menos em nível de espacialização, e não necessariamente em ordem temporal. Além disso, forma-se eixos de contaminação e incidência por 100 mil habitantes, ao longo de trechos das principais rodovias e no entorno de Imperatriz e Marabá. Destaque para a rota composta pela BR 155, PA 287 e a Vicinal PA Bannach e a T0 336 que liga Marabá à BR 153. Nessa rota estão a proporção de notificação por 100 mil habilitante é a mais alta da região considerada.

Diferentemente desse padrão de difusão do vírus, que mostra concentração em alguns pontos do território, o medo, constituinte do imaginário social, não conhece localização. Ele se constitui na principal imagem mental a partir da qual os sujeitos desses locais se relacionam com a Pandemia, independente da cidade que reside e dos casos nela notificados. Isso acontece, além da própria natureza do imaginário, pela difusão de informações veiculadas por diferentes sujeitos com alteridades simbólica, e a difusão massiva de informações sobre a pandemia por meio de redes sociais e da televisão.

Mesmo considerando um evento em processo, a pesquisa aponta a tendência na correlação a malha rodoviária e os seus fluxos populacionais como um importante elemento no crescimento dos casos de COVID-19. Por outro lado, a guerra de representação instaurada em torno do isolamento social potencializa o medo da pandemia.

\section{REFERÊNCIAS}

AQUINO, N. A. A construção da Belém-Brasília e suas implicações no processo de urbanização do estado do Tocantins. In: Odair Giraldin. (Org.). A (trans)formação histórica do Tocantins. Goiânia: Ed. UFG, 2004, p. 315-350.

BRITO, Eliseu Pereira de; SODRÉ, Reges. Os Desafios no combate ao COVID-19 para Araguaína e sua região de influência. Araguaína (TO), 2020 . Disponível em: https://cleitonpinheiro.com.br/portal/os-desafios-no-combate-ao-covid-19-para-araguaina-e-suaregiao-de-

influencia/?fbclid=IwAROyhWHm3cMSWIIOCISII_HS92J1B0onRuWWexkh1mQUvaSCXFqy1bYsy24. Acessado em 22 de abril de 2020.

CORMINEIRO, O. A ocupação da terra nas narrativas de Carmo Bernardes e José Maria Audrin: sertão dos vales do Araguaia e Tocantins (1900 -1950). Outros Tempos. vol. 12, n. 20, 2015 p. 2955. https://doi.org/10.18817/ot.v12i20.354

DELEMEAU, Jean. História do medo no ocidente 1300-1800: uma cidade sitiada. São Paulo: Companhia das Letras, 2009.

CHARTIER, Roger. A história cultural entre práticas e representações. Lisboa: Difusão Editora, 1988.

JOLY, Fernand. A cartografia. Campinas. Papirus, 1990. 
RAMOS JÚNIOR, D. V. Ensaiando rupturas: professores de História escrevem sobre História da África. In.: SILVA, Norma Lucia da; VIEIRA, Martha Victor (Org.). Ensino de História e Formação continuada. 1ed.Goiânia: Editora da PUC de Goiás, 2013, v. 1, p. 81-91

MARTINELLI, Marcelo. Mapas da geografia e cartografia temática. São Paulo: Contexto, 2009.

NEUZA/UFT, Coronavírus - COVID19. Araguaína (TO): NEUZA-UFT. Núcleo de Pesquisa e Extensão em Saberes e Práticas Agroecológicas - Universidade Federal do Tocantins. 2020b. Disponível em: https://youtu.be/Zu5jKei76xw - https://youtu.be/ZxM 9qvMBFA - https://youtu.be/ZxM 9qvMBFA

SANTOS, Milton. A natureza do espaço. São Paulo: Hucitec, 1996.

SILVA, Luis Gustavo Teixeira da. (2019). Laicidade do Estado: dimensões analítico-conceituais e suas estruturas normativas de funcionamento. Sociologias. V. 21, n. 51, pp. 278-304. Epub August 26, 2019. https://doi.org/10.1590/15174522-0215113

UFT. Notícia sobre ações do NEUZA. Palmas (TO): Universidade Federal do Tocantins, 2020. Disponível em: https://ww2.uft.edu.br/index.php/ultimas-noticias/27108-projeto-neuza-desenvolvemateriais-ilustrativos-com-recomendacoes-para-evitar-a-covid-19.

VELHO, Otávio Guilherme. Frentes de expansão: estudo de penetração numa área da Transamazônica. Manaus: UEA Edições, 2013.

VITAL, Fernanda. Análise gráfica de professora da UFT mostra proporção de Covid-19 em Araguaína acima do Tocantins - Jornal do Tocantins. Disponível em: https://www.jornaldotocantins.com.br/editorias/vida-urbana/an\%C3\%A1lise-gr\%C3\%A1fica-deprofessora-da-uft-mostra-propor\%C3\%A7\%C3\%A3o-de-covid-19-em-aragua\%C3\%ADna-acima-dotocantins-1.2044729. Acessado em 30 de abril de 2020. 